\title{
ERN1 knockdown modifies the impact of glucose and glutamine deprivations on the expression of EDN1 and its receptors in glioma cells
}

\author{
Dmytro O. Minchenko, ${ }^{1,2}$, Olena O. Khita ${ }^{1}$, Dariia O. Tsymbal ${ }^{1}$, Yuliia M. Viletska ${ }^{1}$, \\ Myroslava Y. Sliusar ${ }^{1}$, Yuliia V. Yefimova ${ }^{1}$, Liudmyla O. Levadna ${ }^{2}$, Dariia A. KrasnYtsKa ${ }^{1}$, \\ Oleksandr H. MinCHENKo ${ }^{1}$
}

${ }^{1}$ Palladin Institute of Biochemistry, National Academy of Sciences of Ukraine, Kyiv, Ukraine; ${ }^{2}$ National Bogomolets Medical University, Kyiv, Ukraine

E-mail:ominchenko@yahoo.com

Objective. The aim of the present investigation was to study the impact of glucose and glutamine deprivations on the expression of genes encoding EDN1 (endothelin-1), its cognate receptors (EDNRA and EDNRB), and ECE1 (endothelin converting enzyme 1) in U87 glioma cells in response to knockdown of ERN1 (endoplasmic reticulum to nucleus signaling 1), a major signaling pathway of endoplasmic reticulum stress, for evaluation of their possible implication in the control of glioma growth through ERN1 and nutrient limitations.

Methods. The expression level of EDN1, its receptors and converting enzyme 1 in control U87 glioma cells and cells with knockdown of ERN1 treated by glucose or glutamine deprivation by quantitative polymerase chain reaction was studied.

Results. We showed that the expression level of EDN1 and ECE1 genes was significantly upregulated in control U87 glioma cells exposure under glucose deprivation condition in comparison with the glioma cells, growing in regular glucose containing medium. We also observed upregulation of ECE1 gene expression in U87 glioma cells exposure under glutamine deprivation as well as down-regulation of the expression of EDN1 and EDNRA mRNA, being more significant for EDN1. Furthermore, the knockdown of ERN1 signaling enzyme function significantly modified the response of most studied gene expressions to glucose and glutamine deprivation conditions. Thus, the ERN1 knockdown led to a strong suppression of EDN1 gene expression under glucose deprivation, but did not change the effect of glutamine deprivation on its expression. At the same time, the knockdown of ERN1 signaling introduced the sensitivity of EDNRB gene to both glucose and glutamine deprivations as well as completely removed the impact of glucose deprivation on the expression of ECE1 gene.

Conclusions. The results of this study demonstrated that the expression of endothelin-1, its receptors, and ECE1 genes is preferentially sensitive to glucose and glutamine deprivations in gene specific manner and that knockdown of ERN1 significantly modified the expression of EDN1, $E D N R B$, and $E C E 1$ genes in U87 glioma cells. It is possible that the observed changes in the expression of studied genes under nutrient deprivation may contribute to the suppressive effect of ERN1 knockdown on glioma cell proliferation and invasiveness.

Key words: ERN1 knockdown, mRNA expression, EDN1, EDNRA, EDNRB, ECE1, glucose and glutamine deprivations, U87 glioma cells

Corresponding author: Oleksandr H. Minchenko, Prof, Department of Molecular Biology, Palladin Institute of Biochemistry, National Academy of Sciences of Ukraine, Leontovycha 9, Kyiv 01030, Ukraine; e-mail: ominchenko@yahoo.com. 
The unfolded protein response is a highly conserved protein quality control mechanism, activated in response to endoplasmic reticulum stress. The growing tumor requires the endoplasmic reticulum stress for own neovascularization and growth as well as for inhibition of apoptosis under stressful environmental conditions (Drogat et al. 2007; Auf et al. 2010; Doultsinos et al. 2017). The endoplasmic reticulum stress signaling represents an integrated signal transduction pathway that transmits information about the protein folding status at the endoplasmic reticulum to the nucleus and cytosol to restore proteostasis (Bravo et al. 2013; Chevet et al. 2015; Lhomond et al. 2018; Marciniak 2019). Malignant tumors use the unfolded protein response and its signaling pathways to augment cancer cells proliferation (Dejeans et al. 2015; Manie et al. 2014; Papaioannou et al. 2018). It is interesting to note that stimulation of ERN1/IRE1 (endoplasmic reticulum to nucleus signaling 1 /inositol requiring enzyme 1 ) division of the endoplasmic reticulum stress response is tightly linked to apoptosis and cell death, and inhibition of its functional activity has been demonstrated to result in substantial anti-proliferative effect in glioma growth (Auf et al. 2010, 2013; Johnson et al. 2011; Minchenko et al. 2014, 2015c; Markouli et al. 2020). Additionally, suppression of ERN1 endoribonuclease has more robust anti-proliferative influence on glioma cells and preferentially different impact on the expression of some ERN1-related pathway genes (Auf et al. 2013; Minchenko et al. 2015c).

Glioblastoma multiforme is the most common and malignant type of primary brain tumor of the central nervous system with poor prognosis and high mortality. The current clinical treatments for glioblastoma consist of tumor resection, radiotherapy, and chemotherapy (Nayak and Reardon 2017; Almanza et al. 2019; Yang et al. 2020). The rapid growth of cancers generates microenvironmental changes in regards to nutrient deprivation, thus inducing the activation of endoplasmic reticulum stress signaling pathways, cell proliferation, and survival (Obacz et al. 2017; Zhao et al. 2017; Obiedat et al. 2019; Liu et al. 2020). Furthermore, a better knowledge of tumor responses to nutrient deprivation is required to elaborate better therapeutical strategies of cell sensibilization, based on the blockade of survival mechanisms (Iurlaro et al. 2017; Riabovol et al. 2019; Teramoto and Katoh 2019; Minchenko et al. 2020a, b; Ratushna 2020). Cell proliferation and apoptosis are strongly dependent on glycolysis and glucose level, because there is the molecular connection between metabolism, cell cycle progression, and the delivery of nutrients essen- tial for this purpose (Huber et al. 2013; Parzych et al. 2019). Glucose as well as glutamine are important substrates for glycolysis and glutaminolysis, which are important to glioma development and a more aggressive behavior through regulation of the cell cycle at distinct stages (Colombo et al. 2011).

It is interesting to note that endoplasmic reticulum stress and glucose as well as glutamine level are very important and complementary factors for tumor growth and that ERN1 mediated stress signaling can significantly modify the effects of glutamine and glucose deprivations as well as hypoxia on numerous gene expressions (Minchenko et al. 2014, 2016, 2017; 2019; Zhao et al. 2017; Tsymbal et al. 2020). However, the detailed molecular mechanisms of the interaction of hypoxia and glucose deprivation with ERN1 mediated stress signaling pathway are complex yet and warrant further study.

The peptide hormone endothelin-1 (EDN1; ET-1) and its related receptors, such as EDNRA and EDNRB, play an important role not only in the maintenance of vascular tone, but they are also localized to non-vascular structures including epithelial cells, glia and neurons and play multiple, complex roles (Dashwood and Loesch 2009; Khimji and Rockey 2010; Stow et al. 2011). Endothelin-1 and its receptors also have co-mitogenic activity, potentiating the effects of other growth factors such as PDGF and have been linked to variable diseases including diabetes, traumatic shock, and tumorigenesis (Minchenko et al. 1999, 2003; Dashwood and Loesch 2009; Khimji and Rockey 2010; Stow et al. 2011; Palmer et al. 2012; Cook et al. 2015; Dojo Soeandy et al. 2019). There are also data indicating that EDN1 is a neuropeptide, which is implicated in a number of neural circuits where its transmitter affects range from a role in pain and temperature control to its action on the hypothalamo-neurosecretory system (Dashwood and Loesch 2009). Recently, it was shown that mRNA levels encoding EDN1 and its receptors, known to be elevated in amyotrophic lateral sclerosis, were sharply increased by knockdown of C9 (C9ORF72) gene, which encodes a protein that functions in control of endothelin and glutamate signaling (Fomin et al. 2018). Differential and tissue-specific production of EDN1 must be tightly regulated in order to preserve these biologically diverse actions.

It is interesting to note that the palmitic acid increases ET-1 expression in endothelial cells through the induction of endoplasmic reticulum stress and the activation of protein kinase $\mathrm{C}$, providing a novel mechanistic insight into the pathogenesis of obesityassociated hypertension and cardiovascular diseases 
including atherosclerosis (Zhang et al 2018). The primary mechanism thought the control of EDN1 bioavailability is the rate of transcription from the EDN1 gene. Studies conducted on a variety of cell types have identified key transcription factors including HIF that govern EDN1 expression (Aversa et al. 1997; Minchenko and Caro 2000; Stow et al. 2011).

The endothelin receptor type A plays a role in potent and long-lasting vasoconstriction and cell proliferation. Thus, Arabanian et al. (2018) have shown that overexpression of EDNRA led to an increased proliferation and resistance to apoptosis of bone marrow cells in vitro and that MEIS1 binds to the EDNRA promoter region, suggesting a regulatory role for MEIS1 in endothelin-1 receptor type A expression and in HOXA9/MEIS1-driven leukemogenesis. Furthermore, the endothelin axis (EDN1 and EDN1 receptor A) is involved in cellular growth, differentiation, cell motility, invasiveness, and tumor progression as well as drug resistance in several cancers. Polymorphisms of these genes increase the risk of papillary thyroid cancer developing (Aydin et al. 2019; Pulido et al. 2020). Recently, it was observed an abnormal expression of endothelin receptor type B (EDNRB) in hepatocellular carcinoma and confirmed its potential clinical significance (Zhang et al. 2019). Thus, endothelin-1 receptor blockade is a new possible therapeutic approach in ovarian cancer and multiple myeloma, because the majority of multiple myeloma cell lines and primary malignant plasma cells express high levels of EDNRA and EDNRB and release EDN1 (Rosano et al. 2017; Russignan et al. 2017).

The endothelin-converting enzyme-1 (ECE1) is also involved in proteolytic processing of endothelin precursor to biologically active peptide. Active EDN1 has a short half-life, so its biological effects are completely dependent on its enzymatic activation by ECE1. There are data indicating that expression of $E C E 1$ gene is elevated in several tumors and cancer cell lines and that this protein has relation to cancer cell proliferation and invasiveness (Niechi et al. 2015; Tapia and Niechi 2019). Furthermore, Miners and Love (2017) have shown that endothelin-converting enzymes degrade alpha-synuclein and are reduced in dementia with Lewy bodies. Thus, it participates in the metabolism of $a$-synuclein that could contribute to the development and progression of dementia. It is interesting to note that miR-199a-5p, which negatively regulated ECE1, and silencing the ECE1 gene are protected the rat spinal cord injury after ischemia-reperfusion (Bao et al. 2018). The ECE1 gene is hypoxia responsible. Its promoter and intron regions contain the HIF binding sites (Khamaisi et al. 2015). It has also been shown that endothelin-1 production is controlled by TIMAP-protein phosphatase 1-complex via ECE1 dephosphorylation (Boratko et al. 2016).

The aim of this study was to examine the impact of glucose and glutamine deprivations on the expression of genes encoded EDN1, its receptors, and converting enzyme 1 in U87 glioma cells in response to knockdown of ERN1 activity for evaluation of their possible significance in the control of glioma growth through endoplasmic reticulum stress signaling mediated by IRE1 and nutrient limitation.

\section{Materials and methods}

Cell lines and culture conditions. The glioma cell line U87 was obtained from ATCC (USA) and grown in high glucose ( $4.5 \mathrm{~g} / \mathrm{l})$ Dulbecco's modified Eagle's minimum essential medium (Gibco, Invitrogen, Carlsbad, CA, USA) supplemented with glutamine (2 mM), 10\% fetal bovine serum (Equitech-Bio, Inc., USA), penicillin (100 units/ml; Gibco) and streptomycin $\left(0.1 \mathrm{mg} / \mathrm{ml}\right.$; Gibco) at $37^{\circ} \mathrm{C}$ in incubator with $5 \% \mathrm{CO}_{2}$. In this work, we used two sublines of these cells, which were described previously (Auf et al. $2010,2013)$. One subline was obtained by selection of stable transfected clones with overexpression of empty vector pcDNA3.1, which was used for creation of dnERN1. This untreated subline of glioma cells (control glioma cells) was used as control 1 in the study of the effect of glucose and glutamine deprivations on the expression level of genes encoding EDN1, its receptors (EDNRA, EDNRB), and endothelin converting enzyme ECE1. Second subline was obtained by selection of stable transfected clones with overexpression of ERN1 dominant/negative construct (dnERN1), having suppression of both the protein kinase and endoribonuclease activities of this signaling protein (Auf et al. 2010). All used sublines of glioma cells in this study are grown in the presence of geneticin (G418), while these cells carrying empty vector pcDNA3.1 or dnERN1 construct. Glucose and glutamine deprivation conditions were created by changing the complete DMEM medium into culture plates on DMEM medium without glucose or glutamine and plates were exposed to this condition for $16 \mathrm{~h}$.

RNA isolation. Total RNA was extracted from glioma cells using the Trizol reagent according to manufacturer's protocol (Invitrogen, Carlsbad, CA, USA). The RNA pellets were washed with $75 \%$ 
ethanol and dissolved in nuclease-free water. For additional purification RNA samples were re-precipitated with 95\% ethanol and re-dissolved again in nuclease-free water. RNA concentration and spectral characteristics were measured using NanoDrop One Spectrophotometer (Thermo Scientific).

Reverse transcription and quantitative PCR analysis. The impact of glucose and glutamine deprivations on the expression level of endothelin-1 and its receptors (EDNRA and EDNRB) and ECE1 mRNAs as well as ACTB as housekeeping gene were measured in control U87 glioma cells and cells with a deficiency of ERN1, introduced by dnERN1, by quantitative polymerase chain reaction using SYBRGreen Mix (ABgene, Thermo Fisher Scientific, Epsom, Surrey, UK) and "QuantStudio 5 Real-Time PCR System" (Applied Biosystems, USA). Thermo Scientific Verso cDNA Synthesis Kit (Germany) was used for reverse transcription as described previously (Minchenko et al. 2019). Polymerase chain reaction was performed in triplicate. The expression of beta-actin mRNA was used as control of analyzed RNA quantity. The pair of primers specific for each studied gene was received from Sigma-Aldrich (St. Louis, MO, U.S.A.) and used for quantitative polymerase chain reaction as described previously by Minchenko et al. (2019).

Quantitative PCR analysis was performed using a special computer program "Differential expression calculator" and statistical analysis using Excel program and OriginPro 7.5 software as described previously (Bochkov et al. 2006; Rudnytska et al. 2021). Comparison of two means was performed by the use of two-tailed Student's t-test. The value $\mathrm{p}<0.05$ was considered significant in all cases. The values of EDN1, EDNRA, EDNRB, and ECE1 gene expressions were normalized to the expression of beta-actin mRNA and represented as percent of control (100\%). All values are expressed as mean \pm SEM from triplicate measurements performed in 4 independent experiments. The amplified DNA fragments were also analyzed on a $2 \%$ agarose gel and that visualized by SYBR ${ }^{\star}$ Safe DNA Gel Stain (Life Technologies, Carlsbad, CA, USA).

\section{Results}

The possible role of endoplasmic reticulum stress signaling mediated by ERN1 signaling protein in the control of endothelin-1, its receptors, and endothelin converting enzyme 1 gene expressions in U87 glioma cells was studied. As shown in Figure 1, the expression of EDN1 mRNA in control U87 glioma cells (transfected by empty vector), treated by glucose deprivation, is significantly up-regulated $(+57 \%)$ in comparison with non-treated cells. At the same time, inhibition of ERN1 signaling completely modifies the effect of glucose deprivation on the expression of endothelin-1 gene expression (Figure 1). Thus, the exposure of these cells under glucose deprivation leads to a strong down-regulation (-68\%) of EDN1 mRNA expression. We next investigated the effect of ERN1 knockdown on the expression of gene encoding endothelin receptor type A in glioma cells treated by glucose deprivation. As shown in Figure 2, the expression level of EDNRA mRNA is not significantly changed in both control and ERN1 knockdown U87 glioma cells in comparison with cells, growing with glucose. Furthermore, similar results in the expression of EDNRB gene we received in control glioma cells (Figure 3). However, inhibition of ERN1 functional activity by dnERN1 introduces sensitivity of $E D N R B$ gene expression to glucoselimited condition and leads to small but statistically significant up-regulation (+12\%) of this gene expression as compared to appropriate control (dnERN1) glioma cells (Figure 3).

We also studied the expression of gene encoding endothelin converting enzyme 1, which play an

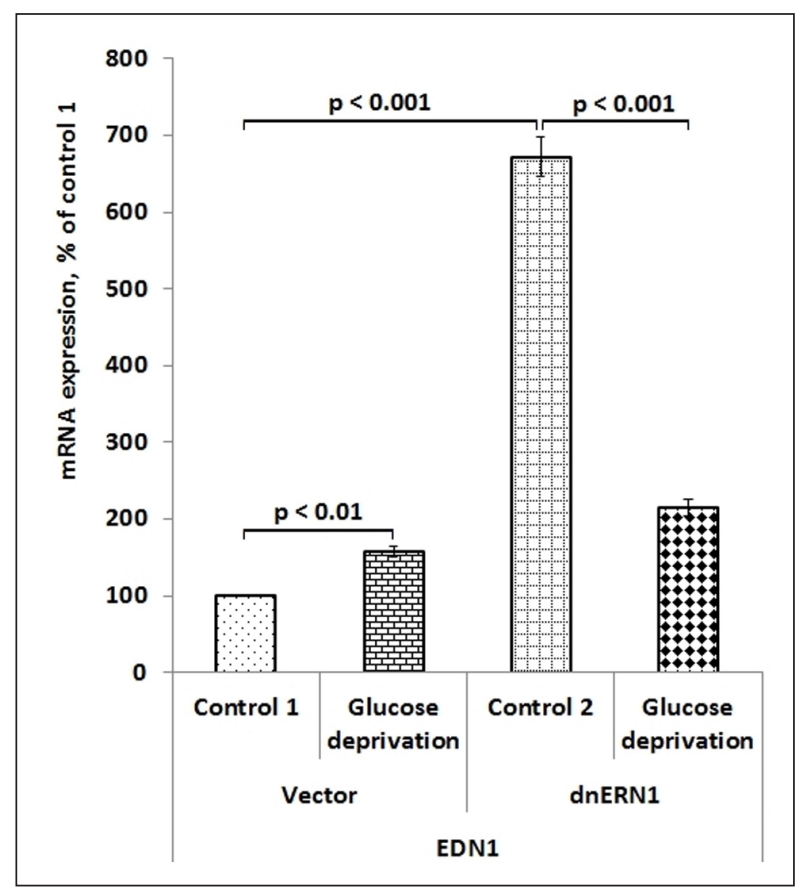

Figure 1. Impact of glucose deprivation on the expression level of endothelin 1 (EDN1) gene expression in control U87 glioma cells (Vector) and cells with a blockade of the ERN1 (dnERN1) measured by qPCR. Values of EDN1 mRNA expression were normalized to the level of beta-actin mRNA and represented as percent of control $1(100 \%) ; n=4$. 


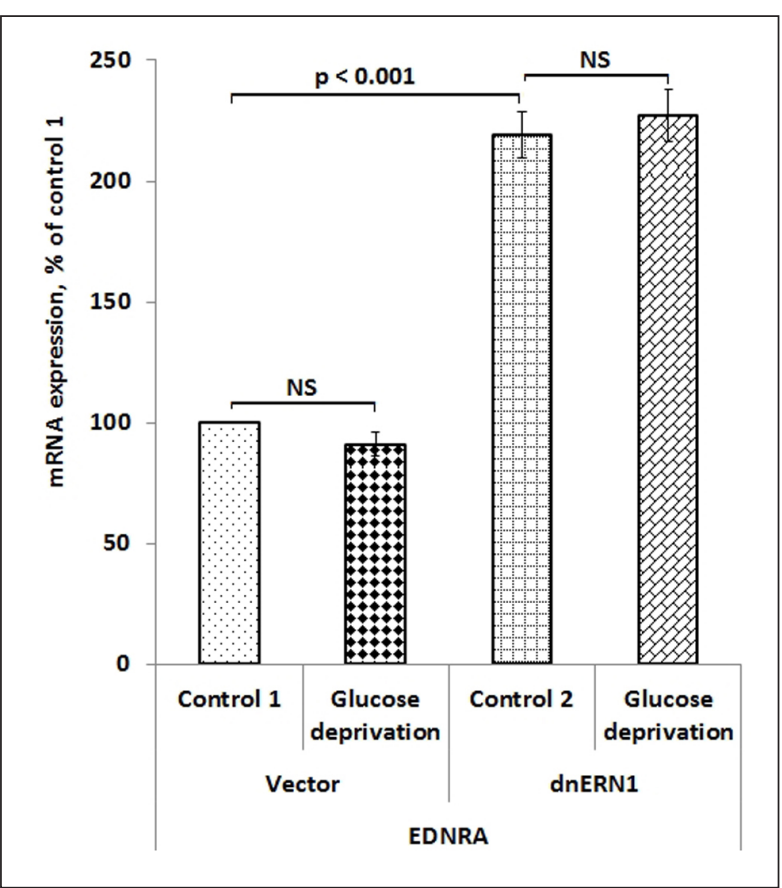

Figure 2. Impact of glucose deprivation on the expression level of endothelin receptor type A (EDNRA) gene expression level in control U87 glioma cells (Vector) and cells with a blockade of the ERN1 (dnERN1) measured by qPCR. Values of EDNRA mRNA expression were normalized to the level of beta-actin mRNA and represented as percent of control $1(100 \%) ; n=4$.

important role in the regulation of endothelin-1 activity and showed its strong sensitivity to glucose deprivation (Figure 4). Thus, the expression level of ECE1 gene is significantly up-regulated $(+133 \%)$ in glioma cells without both ERN1 protein kinase and endoribonuclease activities in comparison with cells, transfected by empty vector. At the same time, knockdown of ERN1 signaling protein completely eliminated the sensitivity of ECE1 gene expression to glucose-limited condition (Figure 4).

We next investigated the impact of glutamine deprivation on the expression of genes encoding endothelin-1 and related proteins in U87 glioma cells in relation to inhibition of ERN1 signaling protein function. It was shown that in control glioma cells (transfected by empty vector) the expression level of $E D N 1$ gene is strongly down-regulated (-63\%) under glutamine-limited condition in comparison with cells growing in regular DMEM medium (Figure 5). Furthermore, inhibition of ERN1 signaling enzyme function does not significantly change the sensitivity of endothelin-1 gene expression to glutamine deprivation condition as compared to corresponding

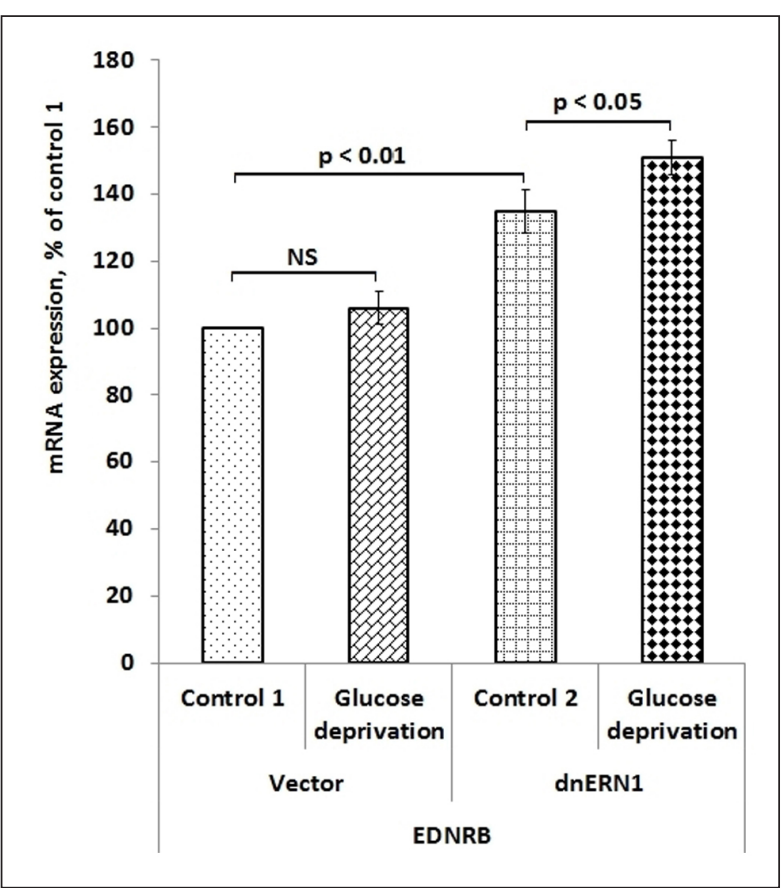

Figure 3. Impact of glucose deprivation on the expression level of endothelin receptor type B (EDNRB) gene expression level in control U87 glioma cells (Vector) and cells with a blockade of the ERN1 (dnERN1) measured by qPCR. Values of EDNRB mRNA expression were normalized to beta-actin mRNA level and represent as percent for control $1(100 \%) ; n=4$.

control cells (dnERN1) (-64\%; Figure 5). At the same time, the impact of glutamine deprivation on the expression of gene encoding endothelin receptor type $\mathrm{A}$ and $\mathrm{B}$ genes in control glioma cells was different (Figures 6 and 7). Thus, the exposure of control glioma cells under glutamine-limited condition leads to down-regulation of EDNRA gene expression (-20\%) but EDNRB gene expression was resistant to this experimental condition. It is interesting to note that inhibition of ERN1 signaling enzyme function modifies effect of glutamine deprivation on endothelin receptor type $\mathrm{B}$ gene expression and leads to up-regulation of the expression of this endothelin receptor gene $(+38 \%)$ in comparison to appropriate control cells (Figure 7). As shown in Figure 8, the exposure of control glioma cells under glutaminelimited condition leads to significant up-regulation of endothelin converting enzyme 1 gene expression $(+37 \%)$ in comparison with control cells growing with glutamine-containing medium. At the same time, the inhibition of ERN1 functional activity decreases the sensitivity of ECE1 gene expression to glutamine deprivation. Therefore, the expression level of ECE1 


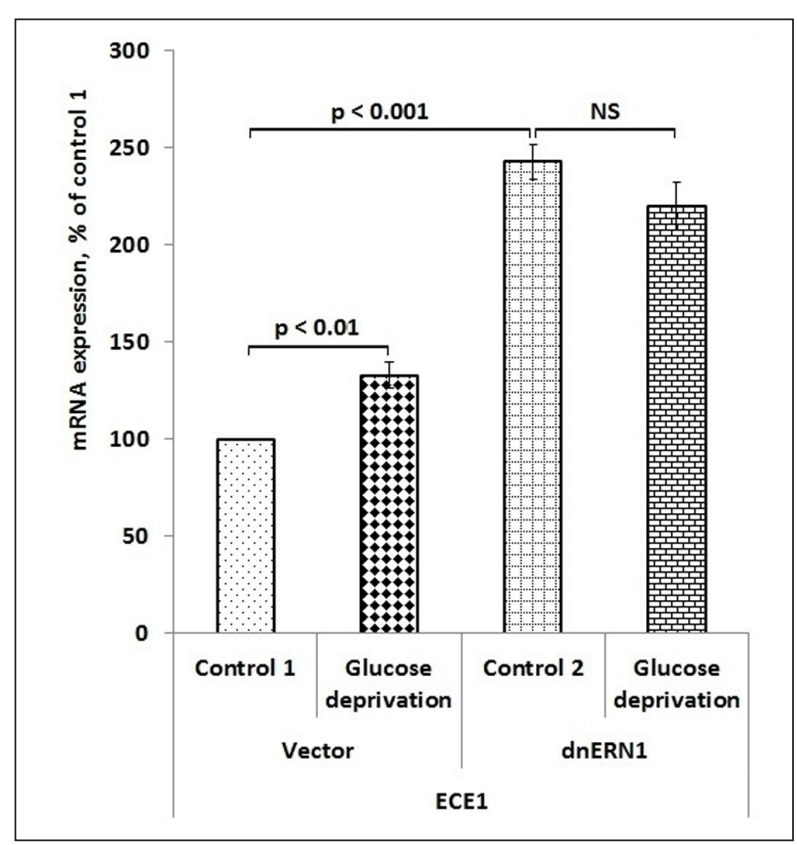

Figure 4. Impact of glucose deprivation on the expression level of endothelin converting enzyme 1 (ECE1) gene expression level in control U87 glioma cells (Vector) and cells with a blockade of the ERN1 (dnERN1) measured by qPCR. Values of ECE1 mRNA expression were normalized to beta-actin mRNA level and represented as percent for control $1(100 \%) ; n=4$.

gene in ERN1 knockdown glioma cells growing under glutamine deprivation condition is also increased but to a much lesser extent ( $+18 \%$; Figure 8$)$.

Thus, the glucose and glutamine deprivation affects the expression of most studied genes but in different ways and preferentially in ERN1 dependent manner.

\section{Discussion}

In this work, we studied the impact of glucose and glutamine deprivation on the expression of genes encoding endothelin-1, its receptors (EDNRA and EDNRB) and endothelin converting enzyme 1, which have relation to functional activity of EDN1, in relation to inhibition of ERN1, the major signaling pathway of the unfolded protein response, in U87 glioma cells with ERN1 knockdown, introduced by dnERN1. Results of these experiments are summarized in Figure 9. These data are important for evaluation of possible significance of these genes in the control of glioma growth through endoplasmic reticulum stress signaling mediated by ERN1, because this stress signaling pathway is involved in numerous metabolic pathways and inhibition of ERN1 signaling enzyme activity in glioma cells had

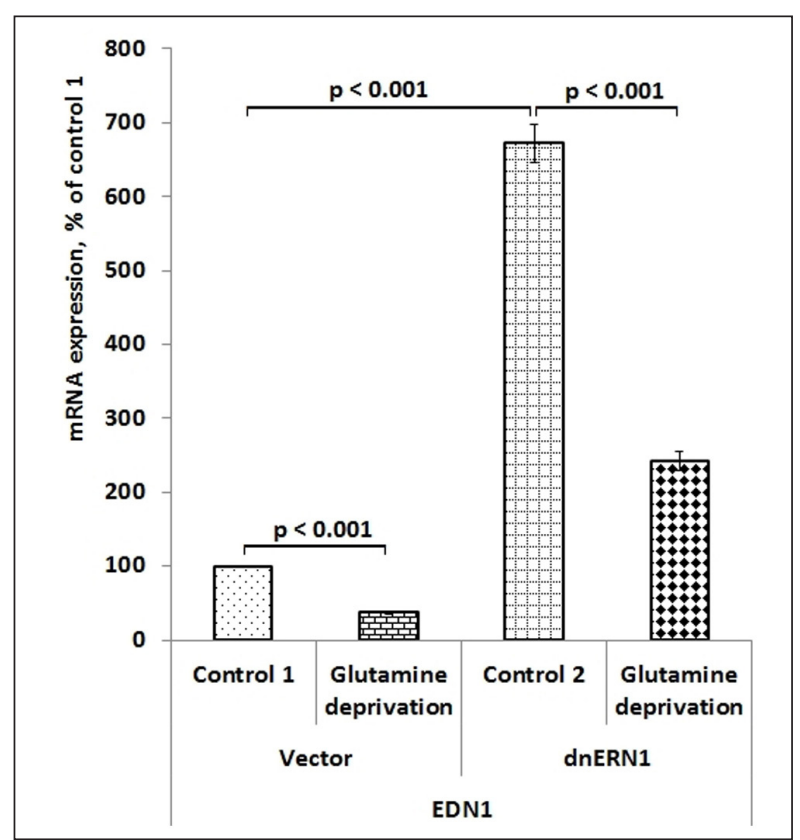

Figure 5. Impact of glutamine deprivation on the expression level of EDN1 mRNA in control U87 glioma cells (Vector) and ERN1 knockdown glioma cells (dnERN1) measured by qPCR. Values of EDN1 mRNA expression were normalized to betaactin mRNA level and represented as percent for control 1 $(100 \%) ; n=4$.

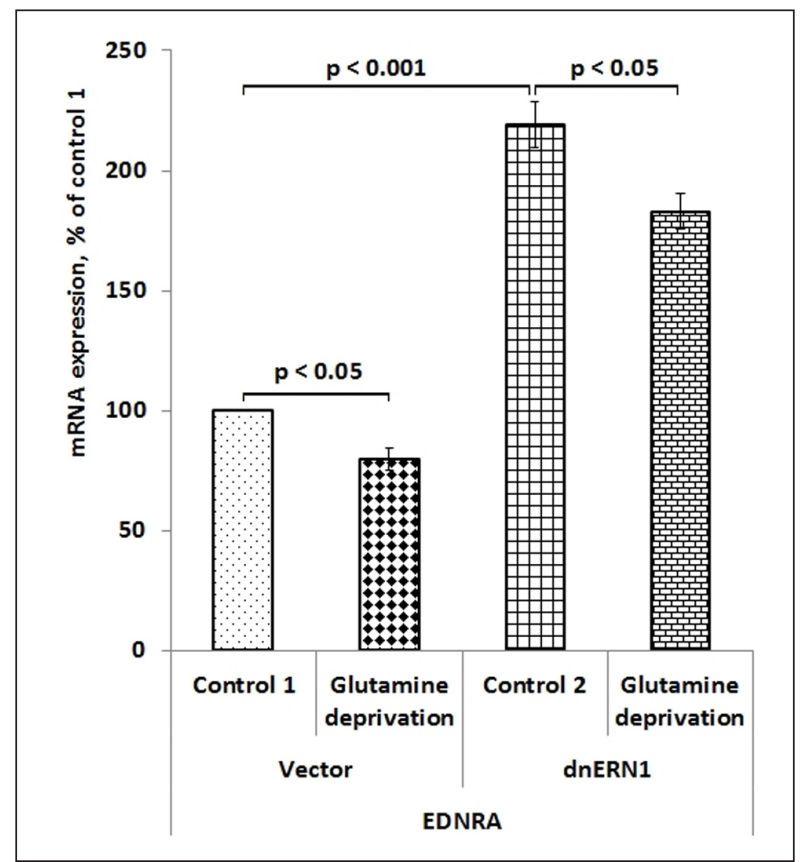

Figure 6. Impact of glutamine deprivation on the expression level of EDNRA mRNA in control U87 glioma cells (Vector) and ERN1 knockdown glioma cells (dnERN1) measured by qPCR. Values of this mRNA expression were normalized to beta-actin mRNA level and represented as percent for control $1(100 \%) ; n=4$. 


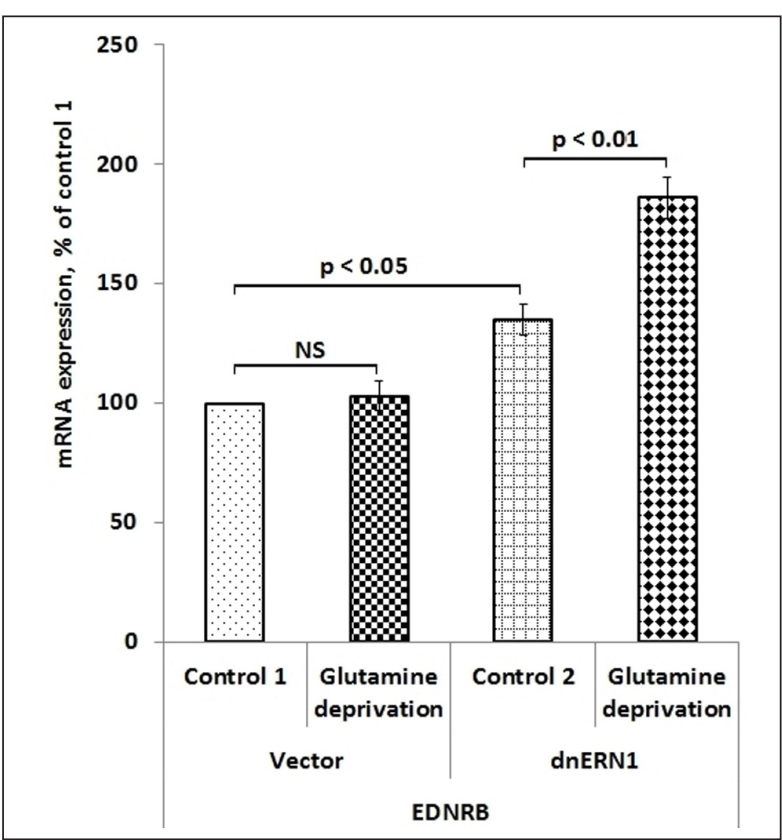

Figure 7. Impact of glutamine deprivation on the expression level of EDNRB mRNA in control U87 glioma cells (Vector) and ERN1 knockdown glioma cells (dnERN1) measured by qPCR. Values of EDNRB mRNA expression were normalized to beta-actin mRNA level and represented as percent for control $1(100 \%) ; n=4$.
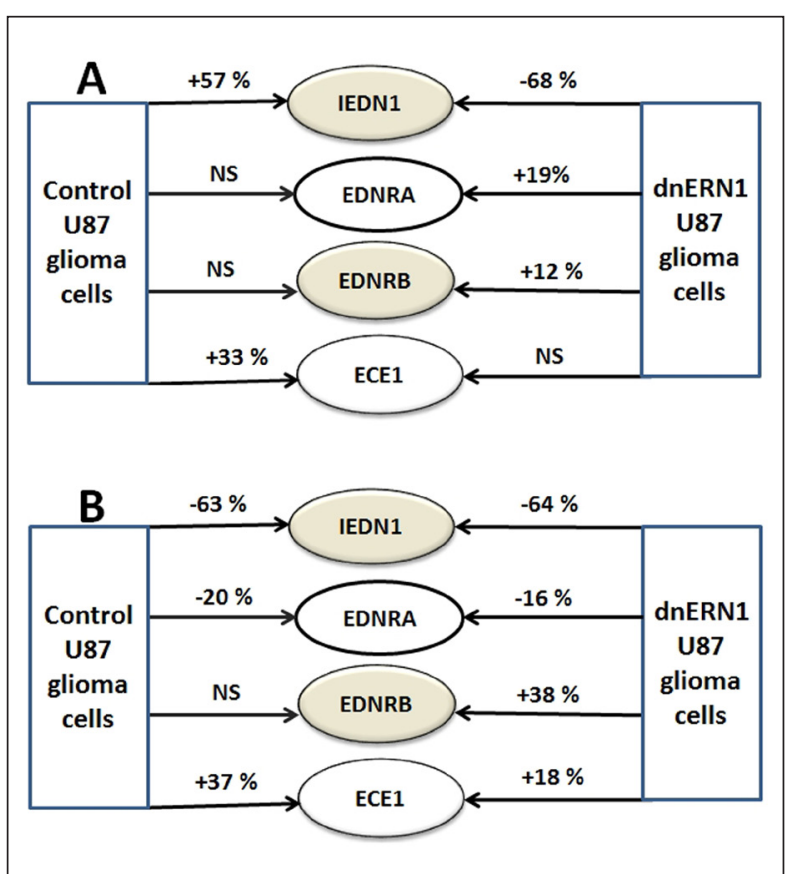

Figure 9. Schematic demonstration of glucose (A) and glutamine deprivations (B) on EDN1, EDNRA, EDNRB, and ECE1 genes expression profile in control and ERN1 knockdown glioma cells; NS - no significant changes.

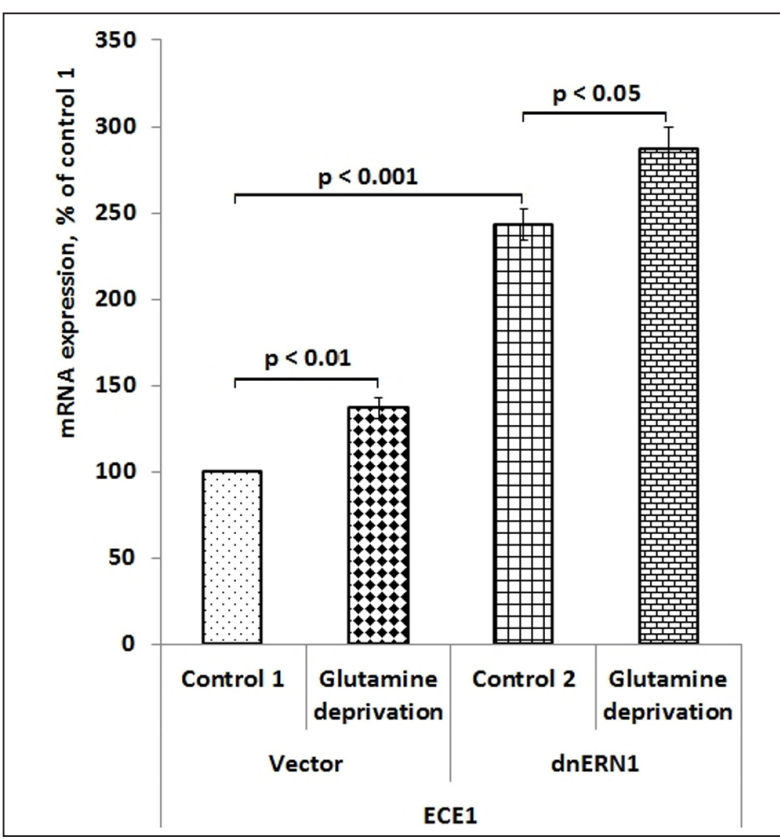

Figure 8. Impact of glutamine deprivation on the expression level of ECE1 mRNA in control U87 glioma cells (Vector) and ERN1 knockdown glioma cells (dnERN1) measured by qPCR. Values of this mRNA expression were normalized to beta-actin mRNA level and represented as percent for control 1 (100\%); $\mathrm{n}=4$.

clear anti-tumor effects (Auf et al. 2010, 2013; Bravo et al. 2013; Manie et al. 2014; Minchenko et al. 2013, 2015a, b; Logue et al. 2018).

Recently, we showed that the expression of EDN1, its receptors, and ECE1 genes is responsible to endoplasmic reticulum stress signaling mediated by ERN1. However, molecular mechanisms of changes in these genes' expression are different (Minchenko et al. 2019). Thus, the expression of EDNRA and ECE1 genes is regulated by ERN1 endoribonuclease, but EDN1 and EDNRB genes - preferentially by ERN1 protein kinase through mechanisms described by Auf et al. (2013) and Minchenko et al. (2015c). Endoplasmic reticulum stress dependent regulation of EDN1 and related proteins agree well with its involving in cancer biology as well as in many other important processes (Teoh et al. 2014; Cook et al. 2015; Niechi et al. 2015; Tapia and Niechi 2019; Minchenko and Caro 2000; Minchenko et al. 2003). At the same time, the prominent pathophysiological aspects of the endothelin system in glioma cells as well as in astrocytes are not clear yet.

We also showed that glucose deprivation enhanced the expression of EDN1 and ECE1 genes and that knockdown of ERN1 signaling enzyme function 
significantly modified the response of these genes to glucose-limited condition (Figure 9A). It is possible that the ERN1 signaling is very important for induction of these genes' expression under glucose deprivation and in this connection the knockdown of ERN1 removes sensitivity of ECE1 gene to glucoselimited condition and leads to a strong suppression of EDN1 gene expression at this experimental state. At the same time, the expressions of both endothelin receptors are resistant to glucose-limited condition. These data clearly demonstrate that glucose-dependent regulation of endothelin system is preferentially realized through EDN1 and ECE1 gene expressions. It is possible that glucose limitation affects different signaling pathways of endoplasmic reticulum stress and thus changes the ERN1 signaling, because there are data that glucose deprivation alters the proapoptotic PERK-CHOP/GADD153 pathway as well as ATF4-mediated apoptosis (Huber et al. 2013; Iurlaro et al. 2017). Furthermore, there are data that glucose deprivation condition can augment the sensitivity of cancer cells to anti-cancer drugs, particularly arctigenin, which inhibits the growth of numerous cancer cells and induces tumor cell death under glucoselimited condition, possibly by blocking the unfolded protein response (He et al. 2018). Results of our study clarify possible mechanisms of glucose deprivation on the proliferation of ERN1 knockdown glioma cells through specific changes in the expression of genes encoding endothelin-1 and related proteins.

At the same time, we observed a strong suppressive impact of glutamine deprivation on the expres- sion of EDN1 gene and significantly lesser - on ENDRA gene expressions both in control and ERN1 knockdown glioma cells (Figure 9B). It is possible that this effect of glutamine-limited condition on EDN1 and EDNRA gene expressions reflects the sensitivity of these genes to glutamine supply. Thus, these results validate tight interaction of endoplasmic reticulum stress signaling with the delivery of essential nutrients such as glutamine and glucose, which are important substrates for glycolysis and glutaminolysis, as well as glioma growth (Colombo et al. 2011; Huber et al. 2013). However, precise molecular mechanisms are not clear yet and warrant further investigations.

This study provides unique insights into the molecular mechanisms regulating the expression of genes encoding endothelin-1, its receptors, and endothelin converting enzyme 1 in glioma cells under glucose and glutamine deprivations in response to inhibition of ERN1 activity, attesting to the fact that endoplasmic reticulum stress is a necessary component of malignant tumor growth. In this regards, endoplasmic reticulum stress signaling pathways are important targets in combined strategies for glioblastoma therapy (Johnson et al. 2011; Festuccia et al. 2020; Liu et al. 2020; Markouli et al. 2020).

\section{Acknowledgement}

This work was funded by the State Budget Program "Support for the Development of Priority Areas of Scientific Research" (Code: 6541030).

\section{References}

Almanza A, Carlesso A, Chintha C, Creedican S, Doultsinos D, Leuzzi B, Luis A, McCarthy N, Montibeller L, More S, Papaioannou A, Puschel F, Sassano ML, Skoko J, Agostinis P, de Belleroche J, Eriksson LA, Fulda S, Gorman AM, Healy S, Kozlov A, Munoz-Pinedo C, Rehm M, Chevet E, Samali A. Endoplasmic reticulum stress signalling - from basic mechanisms to clinical applications. FEBS J 286, 241-278, 2019.

Arabanian LS, Johansson P, Staffas A, Nilsson T, Rouhi A, Fogelstrand L, Palmqvist L. The endothelin receptor type A is a downstream target of Hoxa9 and Meis1 in acute myeloid leukemia. Leuk Res 75, 61-68, 2018.

AufG, Jabouille A, Guerit S, Pineau R, Delugin M, Bouchecareilh M, Favereaux A, Maitre M, Gaiser T, von Deimling A, Czabanka M, Vajkoczy P, Chevet E, Bikfalvi A, Moenner M. A shift from an angiogenic to invasive phenotype induced in malignant glioma by inhibition of the unfolded protein response sensor IRE1. Proc Natl Acad Sci U S A 107, 15553-15558, 2010.

Auf G, Jabouille A, Delugin M, Guerit S, Pineau R, North S, Platonova N, Maitre M, Favereaux A, Vajkoczy P, Seno M, Bikfalvi A, Minchenko D, Minchenko O, Moenner M. High epiregulin expression in human U87 glioma cells relies on IRE1alpha and promotes autocrine growth through EGF receptor. BMC Cancer 13, 597, 2013.

Aversa CR, Oparil S, Caro J, Li H, Sun S-D, Chen Y-F, Swerdel MR, Monticello TM, Durham SK, Minchenko A, Lira SA, Webb ML. Hypoxia stimulates human preproendothelin-1 promoter activity in transgenic mice. Amer J Physiol 273, L848-L855, 1997. 
Aydin AF, Vural P, Dogru-Abbasoglu S, Cil E. The endothelin 1 and endothelin receptor A gene polymorphisms increase the risk of developing papillary thyroid cancer. Mol Biol Rep 46, 199-205, 2019.

Bao N, Fang B, Lv H, Jiang Y, Chen F, Wang Z, Ma H. Upregulation of miR-199a-5p protects spinal cord against ischemia/reperfusion-induced injury via downregulation of ECE1 in rat. Cell Mol Neurobiol 38, 1293-1303, 2018.

Bochkov VN, Philippova M, Oskolkova O, Kadl A, Furnkranz A, Karabeg E, Breuss J, Minchenko OH, Mechtcheriakova D, Hohensinner P, Rychli K, Wojta J, Resink T, Binder BR, Leitinger N. Oxidized phospholipids stimulate angiogenesis via induction of VEGF, IL-8, COX-2 and ADAMTS-1 metalloprotease, implicating a novel role for lipid oxidation in progression and destabilization of atherosclerotic lesions. Circ Res 99, 900-908, 2006.

Boratko A, Vereb Z, Petrovski G, Csortos C. TIMAP-protein phosphatase 1-complex controls endothelin-1 production via ECE-1 dephosphorylation. Int J Biochem Cell Biol 73, 11-18, 2016.

Bravo R, Parra V, Gatica D, Rodriguez AE, Torrealba N, Paredes F, Wang ZV, Zorzano A, Hill JA, Jaimovich E, Quest AF, Lavandero S. Endoplasmic reticulum and the unfolded protein response: dynamics and metabolic integration. Int Rev Cell Mol Biol 301, 215-290, 2013.

Chevet E, Hetz C, Samali A. Endoplasmic reticulum stress-activated cell reprogramming in oncogenesis. Cancer Discov 5, 586-597, 2015.

Colombo SL, Palacios-Callender M, Frakich N, Carcamo S, Kovacs I, Tudzarova S, Moncada S. Molecular basis for the differential use of glucose and glutamine in cell proliferation as revealed by synchronized HeLa cells. Proc Natl Acad Sci USA 108, 21069-21074, 2011.

Cook N, Brais R, Qian W, Hak CC, Corrie PG. Endothelin-1 and endothelin B receptor expression in pancreatic adenocarcinoma. J Clin Pathol 68, 309-313, 2015.

Dashwood MR, Loesch A. Endothelin-1 as a neuropeptide: neurotransmitter or neurovascular effects? J Cell Commun Signal 4, 51-62, 2009.

Dejeans N, Barroso K, Fernandez-Zapico ME, Samali A, Chevet E. Novel roles of the unfolded protein response in the control of tumor development and aggressiveness. Semin Cancer Biol 33, 67-73, 2015.

Dojo Soeandy C, Salmasi F, Latif M, Elia AJ, Suo NJ, Henderson JT. Endothelin-1-mediated cerebral ischemia in mice: early cellular events and the role of caspase-3. Apoptosis 24, 578-595, 2019.

Doultsinos D, Avril T, Lhomond S, Dejeans N, Guedat P, Chevet E. Control of the unfolded protein response in health and disease. SLAS Discov 22, 787-800, 2017.

Drogat B, Auguste P, Nguyen DT, Bouchecareilh M, Pineau R, Nalbantoglu J, Kaufman RJ, Chevet E, Bikfalvi A, Moenner M. IRE1 signaling is essential for ischemia-induced vascular endothelial growth factor-A expression and contributes to angiogenesis and tumor growth in vivo. Cancer Res 67, 6700-6707, 2007.

Festuccia C, Biordi AL, Tombolini V, Hara A, Bailey D. Targeted molecular therapy in glioblastoma. J Oncology 2020, 5104876, 2020.

Fomin V, Richard P, Hoque M, Li C, Gu Z, Fissore-O’Leary M, Tian B, Prives C, Manley JL. The C9ORF72 gene, implicated in amyotrophic lateral sclerosis and frontotemporal dementia, encodes a protein that functions in control of endothelin and glutamate signaling. Mol Cell Biol 38, e00155-18, 2018.

He Y, Fan Q, Cai T, Huang W, Xie X, Wen Y, Shi Z. Molecular mechanisms of the action of Arctigenin in cancer. Biomed Pharmacother 108, 403-407, 2018.

Huber AL, Lebeau J, Guillaumot P, Petrilli V, Malek M, Chilloux J, Fauvet F, Payen L, Kfoury A, Renno T, Chevet E, Manie SN. p58(IPK)-mediated attenuation of the proapoptotic PERK-CHOP pathway allows malignant progression under low glucose. Mol Cell 49, 1049-1059, 2013.

Iurlaro R, Puschel F, Leon-Annicchiarico CL, O’Connor H, Martin SJ, Palou-Gramon D, Lucendo E, Munoz-Pinedo C. Glucose deprivation induces ATF4-mediated apoptosis through TRAIL death receptors. Mol Cell Biol 37, e00479-16, 2017.

Johnson GG, White MC, Grimaldi M. Stressed to death: targeting endoplasmic reticulum stress response induced apoptosis in gliomas. Curr Pharm Des 17, 284-292, 2011.

Khamaisi M, Toukan H, Axelrod JH, Rosenberger C, Skarzinski G, Shina A, Meidan R, Koesters R, Rosen S, Walkinshaw G, Mimura I, Nangaku M, Heyman SN. Endothelin-converting enzyme is a plausible target gene for hypoxia-inducible factor. Kidney Int 87, 761-770, 2015.

Khimji AK, Rockey DC. Endothelin-biology and disease. Cell. Signal 22, 1615-1625, 2010.

Lhomond S, Avril T, Dejeans N, Voutetakis K, Doultsinos D, McMahon M, Pineau R, Obacz J, Papadodima O, Jouan F, Bourien H, Logotheti M, Jegou G, Pallares-Lupon N, Schmit K, Le Reste PJ, Etcheverry A, Mosser J, Barroso K, Vauleon E, Maurel M, Samali A, Patterson JB, Pluquet O, Hetz C, Quillien V, Chatziioannou A, Chevet E. Dual IRE1 RNase functions dictate glioblastoma development. EMBO Mol Med 10, e7929, 2018. 
Liu K, Tsung K, Attenello FJ. Characterizing cell stress and GRP78 in glioma to enhance tumor treatment. Front Oncol 10, 608911, 2020.

Logue SE, McGrath EP, Cleary P, Greene S, Mnich K, Almanza A, Chevet E, Dwyer RM, Oommen A, Legembre P, Godey F, Madden EC, Leuzzi B, Obacz J, Zeng Q, Patterson JB, Jager R, Gorman AM, Samali A. Inhibition of IRE1 RNase activity modulates the tumor cell secretome and enhances response to chemotherapy. Nat Commun 9, 3267, 2018.

Manie SN, Lebeau J, Chevet E. Cellular mechanisms of endoplasmic reticulum stress signaling in health and disease. 3. Orchestrating the unfolded protein response in oncogenesis: an update. Am J Physiol Cell Physiol 307, C901-C907, 2014.

Marciniak SJ. Endoplasmic reticulum stress: a key player in human disease. FEBS J 286, 228-231, 2019.

Markouli M, Strepkos D, Papavassiliou AG, Piperi C. Targeting of endoplasmic reticulum (ER) stress in gliomas. Pharmacol Res 157, 104823, 2020.

Minchenko AG, Armstead VE, Opentanova IL, Lefer AM. Endothelin-1, endothelin receptors and ecNOS gene expression in vital organs during traumatic shock in rats. Endothelium 6, 303-314, 1999.

Minchenko A, Caro J. Regulation of endothelin-1 gene expression in human microvascular endothelial cells by hypoxia and cobalt: role of hypoxia responsible element. Mol Cell Biochem 208, 53-62, 2000.

Minchenko AG, Stevens MJ, White L, Abatan OI, Komjati K, Pacher P, Szabo C, Obrosova IG. Diabetes-induced overexpression of endothelin-1 and endothelin receptors in the rat renal cortex is mediated via poly(ADPribose)polymerase activation. FASEB J 17, 1514-1516, 2003.

Minchenko DO, Kharkova AP, Hubenia OV, Minchenko OH. Insulin receptor, IRS1, IRS2, INSIG1, INSIG2, RRAD, and BAIAP2 gene expressions in glioma U87 cells with ERN1 loss of function: effect of hypoxia and glutamine or glucose deprivation. Endocr Reg 47, 15-26, 2013.

Minchenko DO, Danilovskyi SV, Kryvdiuk IV, Bakalets TV, Lypova NM, Karbovskyi LL, Minchenko OH. Inhibition of ERN1 modifies the hypoxic regulation of the expression of TP53-related genes in U87 glioma cells. Endoplasm Reticul Stress Dis 1, 18-26, 2014.

Minchenko DO, Kharkova AP, Tsymbal DO, Karbovskyi LL, Minchenko OH. Expression of insulin-like growth factor binding protein genes and its hypoxic regulation in U87 glioma cells depends on ERN1 mediated signaling pathway of endoplasmic reticulum stress. Endocr Reg 49, 73-83, $2015 \mathrm{a}$.

Minchenko DO, Kharkova AP, Tsymbal DO, Karbovskyi LL, Minchenko OH. IRE1 inhibition affects the expression of insulin-like growth factor binding protein genes and modifies its sensitivity to glucose deprivation in U87 glioma cells. Endocr Reg 49, 185-197, 2015b.

Minchenko DO, Tsymbal DO, Riabovol OO, Viletska YM, Lahanovska YO, Sliusar MY, Bezrodnyi BH, Minchenko $\mathrm{OH}$. Hypoxic regulation of EDN1, EDNRA, EDNRB, and ECE1 gene expressions in IRE1 knockdown U87 glioma cells. Endocr Reg 53, 250-262, 2019.

Minchenko DO, Khita OO, Tsymbal DO, Danilovskyi SV, Rudnytska OV, Halkin OV, Kryvdiuk IV, Smeshkova MV, Yakymchuk MM, Bezrodnyi BH, Minchenko OH. Expression of IDE and PITRM1 genes in IRE1 knockdown U87 glioma cells: effect of hypoxia and glucose deprivation. Endocr Reg 54, 183-195, 2020a.

Minchenko OH, Tsymbal DO, Moenner M, Minchenko DO, Kovalevska OV, Lypova NM. Inhibition of the endoribonuclease of ERN1 signaling enzyme affects the expression of proliferation-related genes in U87 glioma cells. Endoplasm Reticul Stress Dis 2, 18-29, 2015c.

Minchenko OH, Kryvdiuk IV, Minchenko DO, Riabovol OO, Halkin OV. Inhibition of IRE1 signaling affects expression of a subset genes encoding for TNF-related factors and receptors and modifies their hypoxic regulation in U87 glioma cells. Endoplasm Reticul Stress Dis 3, 1-15, 2016.

Minchenko OH, Luzina OY, Hnatiuk OS, Minchenko DO, Garmash YA, Ratushna OO. Expression of tumor growth related genes in IRE1 knockdown U87 glioma cells: effect of hypoxia. Ukr Biochem J 89, 40-51, 2017.

Minchenko OH, Hnatiuk OS, Tsymbal DO, Viletska YM, Danilovskyi SV, Halkin OV, Kryvdiuk IV, Rudnytska OV. ERN1 depended regulation of TMED10, MYL9, SPOCK1, CUL4A and CUL4B gene expressions by glucose and glutamine deprivations in U87 glioma cells. Ukr Biochim J 92, 50-61, 2020 b.

Miners JS, Love S. Endothelin-converting enzymes degrade alpha-synuclein and are reduced in dementia with Lewy bodies. J Neurochem 141, 275-286, 2017.

Nayak L, Reardon DA. High-grade Gliomas. Continuum (Minneap Minn) 23, 1548-1563, 2017.

Niechi I, Silva E, Cabello P, Huerta H, Carrasco V, Villar P, Cataldo LR, Marcelain K, Armisen R, Varas-Godoy M, Fernandez C, Tapia JC. Colon cancer cell invasion is promoted by protein kinase CK2 through increase of endothelin-converting enzyme-1c protein stability. Oncotarget 6, 42749-42760, 2015. 
Obacz J, Avril T, Le Reste PJ, Urra H, Quillien V, Hetz C, Chevet E. Endoplasmic reticulum proteostasis in glioblastoma-From molecular mechanisms to therapeutic perspectives. Sci Signal 10, eaal2323, 2017.

Obiedat A, Seidel E, Mahameed M, Berhani O, Tsukerman P, Voutetakis K, Chatziioannou A, McMahon M, Avril T, Chevet E, Mandelboim O, Tirosh B. Transcription of the NKG2D ligand MICA is suppressed by the IRE1/ XBP1 pathway of the unfolded protein response through the regulation of E2F1. FASEB J 33, 3481-3495, 2019.

Palmer JC, Barker R, Kehoe PG, Love S. Endothelin-1 is elevated in Alzheimer's disease and upregulated by amyloid- $\beta$. J Alzheimers Dis 29, 853-861, 2012.

Papaioannou A, Chevet E. Driving cancer tumorigenesis and metastasis through UPR signaling. Curr Top Microbiol Immunol 414, 159-192, 2018.

Parzych K, Saavedra-Garcia P, Valbuena GN, Al-Sadah HA, Robinson ME, Penfold L, Kuzeva DM, Ruiz-Tellez A, Loaiza S, Holzmann V, Caputo V, Johnson DC, Kaiser MF, Karadimitris A, Lam EW, Chevet E, Feldhahn N, Keun HC, Auner HW. The coordinated action of VCP/p97 and GCN2 regulates cancer cell metabolism and proteostasis during nutrient limitation. Oncogene 38, 3216-3231, 2019.

Pulido I, Ollosi S, Aparisi S, Becker JH, Aliena-Valero A, Benet M, Rodriguez ML, Lopez A, Tamayo-Torres E, Chulia-Peris L, Garcia-Canaveras JC, Soucheray M, Dalheim AV, Salom JB, Qiu W, Kaja S, Fernandez-Coronado JA, Alandes S, Alcacer J, Al-Shahrour F, Borgia JA, Juan O, Nishimura MI, Lahoz A, Carretero J, Shimamura T. Endothelin-1-mediated drug resistance in EGFR-mutant non-small cell lung carcinoma. Cancer Res 80, 4224-4232, 2020.

Ratushna OO. Glucose deprivation affects the expression of genes encoding cAMP-activated protein kinase and related proteins in U87 glioma cells in ERN1 dependent manner. Endocr Reg 54, 244-254, 2020.

Riabovol OO, Tsymbal DO, Minchenko DO, Lebid-Biletska KM, Sliusar MY, Rudnytska OV, Minchenko OH. Effect of glucose deprivation on the expression of genes encoding glucocorticoid receptor and some related factors in ERN1-knockdown U87 glioma cells. Endocr Reg 53, 237-249, 2019.

Rosano L, Cianfrocca R, Sestito R, Tocci P, Di Castro V, Bagnato A. Targeting endothelin-1 receptor/ $\beta$-arrestin1 network for the treatment of ovarian cancer. Expert Opin Ther Targets 21, 925-932, 2017.

Rudnytska OV, Khita OO, Minchenko DO, Tsymbal DO, Yefimova YV, Sliusar MY, Minchenko OH. The low doses of SWCNTs exhibit a genotoxic effect on the normal human astrocytes by disrupting the functional integrity of the genome. Currr Res Toxicol 2, 64-71, 2021.

Russignan A, Spina C, Tamassia N, Cassaro A, Rigo A, Bagnato A, Rosano L, Bonalumi A, Gottardi M, Zanatta L, Giacomazzi A, Scupoli MT, Tinelli M, Salvadori U, Mosna F, Zamo A, Cassatella MA, Vinante F, Tecchio C. Endothelin-1 receptor blockade as new possible therapeutic approach in multiple myeloma. Br J Haematol 178, 781-793, 2017.

Stow LR, Jacobs ME, Wingo CS, Cain BD. Endothelin-1 gene regulation. FASEB J 25, 16-28, 2011.

Tapia JC, Niechi I. Endothelin-converting enzyme-1 in cancer aggressiveness. Cancer Lett 452, 152-157, 2019.

Teramoto K, Katoh H. The cystine/glutamate antiporter xCT is a key regulator of EphA2 S897 phosphorylation under glucose-limited conditions. Cell Signal 62, 109329, 2019.

Teoh JP, Park KM, Wang Y, Hu Q, Kim S, Wu G, Huang S, Maihle N, Kim IM. Endothelin-1/endothelin A receptormediated biased signaling is a new player in modulating human ovarian cancer cell tumorigenesis. Cell Signal 26, 2885-2895, 2014.

Tsymbal DO, Minchenko DO, Khita OO, Rudnytska OV, Viletska YM, Lahanovska YO, He Q, Liu K, Minchenko $\mathrm{OH}$. ERN1 knockdown modifies the effect of glucose deprivation on homeobox gene expressions in U87 glioma cells. Endocr Reg 54, 196-206, 2020.

Yang J, Shi Z, Liu R, Wu Y, Zhang X. Combined-therapeutic strategies synergistically potentiate glioblastoma multiforme treatment via nanotechnology. Theranostics 10, 3223-3239, 2020.

Zhang J, Zhao WS, Wang X, Xu L, Yang XC. Palmitic acid increases endothelin-1 expression in vascular endothelial cells through the induction of endoplasmic reticulum stress and protein kinase C signaling. Cardiology 140, 133-140, 2018.

Zhang L, Luo B, Dang YW, He RQ, Chen G, Peng ZG, Feng ZB. The clinical significance of endothelin receptor type $B$ in hepatocellular carcinoma and its potential molecular mechanism. Exp Mol Pathol 107, 141-157, 2019.

Zhao S, Cai J, Li J, Bao G, Li D, Li Y, Zhai X, Jiang C, Fan L. Bioinformatic profiling identifies a glucose-related risk signature for the malignancy of glioma and the survival of patients. Mol Neurobiol 54, 8203-8210, 2017. 